\title{
Land Use/Land Cover Changes and Its Response to Hydrological Characteristics in the Upper Reaches of Minjiang River
}

\author{
Kai Ma ${ }^{1,2}$, Xiaorong Huang ${ }^{1,2}$, Biying Guo ${ }^{1,2}$, Yanqiu Wang ${ }^{1,2}$, and Linyun Gao ${ }^{1,2}$ \\ ${ }^{1}$ State Key Laboratory of Hydraulics and Mountain River Engineering, Chengdu, Sichuan, 610065, China \\ ${ }^{2}$ College of Water Resource \& Hydropower, Sichuan University, Chengdu, Sichuan 610065, China \\ Correspondence: Xiaorong Huang (hxiaorong@scu.edu.cn)
}

Received: 30 December 2017 - Revised: 23 March 2018 - Accepted: 23 March 2018 - Published: 5 June 2018

\begin{abstract}
Land use changes alter the hydrological characteristics of the land surface, and have significant impacts on hydrological cycle and water balance, the analysis of complex effects on natural systems has become one of the main concerns. In this study, we generated the land use conversion matrixes using ArcGIS and selected several landscape indexes (contagion index, CONTAG, Shannon's diversity index, SHDI, etc.) to evaluate the impact of land use/cover changes on hydrological process in the upper reaches of Minjiang River. We also used a statistical regression model which was established based on hydrology and precipitation data during the period of 1959-2008 to simulate the impacts of different land use conditions on rainfall and runoff in different periods. Our results showed that the simulated annual mean flow from 1985 to 1995 and 1995 to 2008 are 9.19 and $1.04 \mathrm{~m}^{3} \mathrm{~s}^{-1}$ lower than the measured values, respectively, which implied that the ecological protection measures should be strengthened in the study area. Our study could provide a scientific basis for water resource management and proper land use planning of upper reaches of Minjiang River.
\end{abstract}

\section{Introduction}

With the continuous development of human society, the land use pattern has significantly changed from the basin scale to the global scale, and influenced the biological energy and water cycle processes on earth's surface (Kalnay and Cai, 2003; Lambin et al., 2002). This has been one of most popular scientific issues in this century, which focused on the potential impacts of land use changes on regional resources, environment and sustainable development (Potter, 1991). At the basin scale, the impacts of climate and land use changes on hydrological process would directly induce the changes in water resource supply and demand, and further significantly impact the local ecology, environment and economic development (Wang et al., 2005). Therefore, it is important to have a better understanding about the land use changes and their influence on regional water cycle. However, the impacts of human activities in different time periods and the different geographical features reflected the large inconsistency in response of land use pattern to hydrological process. Thus, a large number of case studies in typical areas are needed to explore the general application theory (Huang and Zhang, 2004).

\section{The Study Area}

As one of main tributaries at upper reach of the Yangtze River, Minjiang River originates from the border of Sichuan and Gansu Provinces on northern foot of Minshan Mountain (Fig. 1). Within the $31-33^{\circ} \mathrm{N}$ and $102-104^{\circ} \mathrm{E}$, its upper reaches are located in the transition zone between hilly Sichuan Basin and Northwest Sichuan Plateau and under the administrative jurisdiction of Wenchuan, Maoxian, Heishui and Songpan Counties in Sichuan Province. The basin area is $22950 \mathrm{~km}^{2}$, with the total river length being $340 \mathrm{~km}$ and average slope being $8.85 \%$. The mean annual discharge and the annual mean flow are $462 \mathrm{~m}^{3} \mathrm{~s}^{-1}$ and 14.57 billion $\mathrm{m}^{3}$, respectively. As upper reaches of Minjiang River are of complicated geological structure, the overall terrain descends from the northwest to the southeast. There are great differ- 


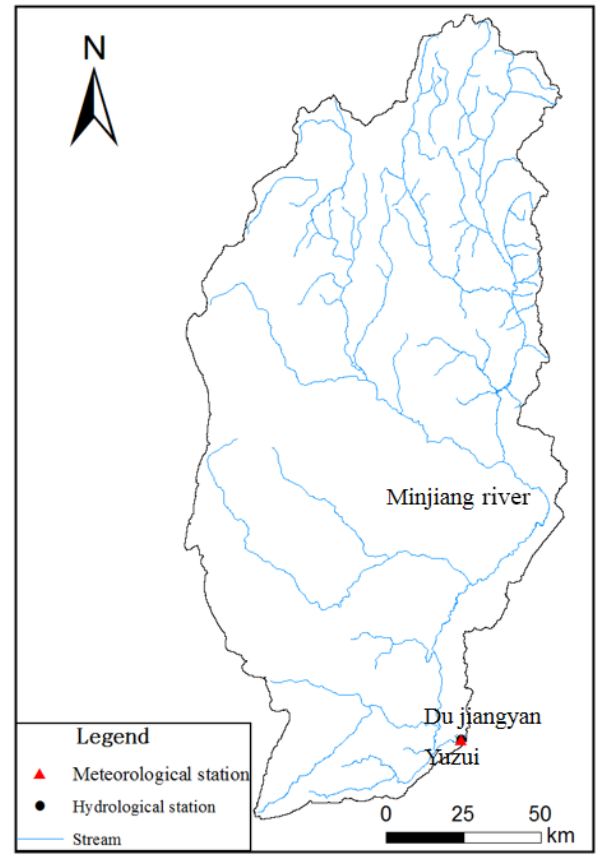

Figure 1. Location of study area and hydrometeorological stations.

ences between proportions of high and low mountains in this area, with average height difference being over $1000 \mathrm{~m}$. For a long time, this area is relatively economically underdeveloped due to great differences in production and life styles of multiple peoples, which also results in diversity of agricultural land use. These provide goods disturbance gradient conditions for study on this land use impacts.

\section{Data}

\subsection{Land use data}

Satellite-based image data in 1985, 1995, 2005 and 2014 are used in this study, with the support of EDARS IMAGINE and ArcGIS software. In this study, land use is divided into 6 types, i.e. arable land, forest land, grass land, water area, land for urban and rural residents and unused land, and subdivided into 20 types, i.e. paddy field, dry land, forest land, shrub, open forest land, other forest land, high coverage grass land, moderate coverage grass land, low coverage grass land, canal, lake, permanent glaciers and snowfield, urban land, rural residential land and swamp.

\subsection{Water and weather data}

The monthly precipitation used in this study was observed by the China Meteorological Administration at Dujiangyan station during 1959-2010, while the monthly runoff data of Yuzui hydrological station in Dujiangyan from 1959 to 2008 were derived from the Survey Bureau of The Hydrology and Water Resources.

\subsection{Analysis on land use pattern changes}

The land use changes in the last two decades was analyzed based on the image data in 1985, 1995, 2005 and 2014. Firstly, The conversion matrix of land use change that established by superimposing the land use image during two different periods was employed to analyze the land use changes (Liu and Zhu, 2010). Then, 7 indexes were selected based on the theory of landscape ecology (Ravan and Roy, 1997; Liu et al., 2005; Xiao and Bu, 1997; Bu et al., 2005) to analyze spatial pattern of land use for upper reaches of Minjiang River, including Patch Density (PD), Edge density (ED), Landscape Shape Index (LSI), Mean Fractal Dimension (FRAC_MN), Contagion Index (CONTAG), Landscape Diversity Index (DIVISION) and Shannon's Diversity Index (SHDI). The detailed physical meaning and calculation of each index could be seen in Bu et al. (2005) and Liu et al. (2005).

\subsection{Response of land use changes to hydrological process}

There are many studies (Zhou et al., 2015; Bewket and Sterk, 2005; Hao and Su, 2015) about the impacts of land use pattern changes on hydrological process, which are mostly statistical analysis for hydrological data and distributed hydrological model simulation analysis based on soil physical and hydrological data. However, it is difficult to collect the data (such as soil physical data) that are necessary for hydrological model establishment. Meanwhile, it is hard to identify the relevant parameters affecting rainfall and runoff process due to different types of vegetation cover (Napoli et al., 2017; Bütof et al., 2015). So while the model analysis with higher simulation precision and physical mechanism, but it is difficult to be suitable in practice, especially in Information deficiency areas. In this study, the statistical regression model is established based on rainfall and runoff data of Dujiangyan Station during 1959-2008 to simulate the impacts different land use conditions on runoff under same precipitation condition.

\section{Results}

\subsection{Characteristics of dynamic changes of land use}

The result from land use data in 1985 and 2014 showed that during the period of 1985-2014, the land was mainly used as grass land and forest land (accounting for over $96 \%$ of total catchment area) at upper reaches of Minjiang River, and then followed by arable land, and others were water area, land for urban and rural residents and unused land (Table 1). In recent 20 years, the grass land area was decreased sharply with the average speed of $351.29 \mathrm{~km}^{2}$ during 1985-2014, while the others land areas were increased. The areas of water area and arable land accounted for 2.56 and $3.38 \%$ of total catchment area in 1985 and 2014, respectively. The areas of arable land 
Table 1. Land use conversion matrix from 1985 to 2014.

\begin{tabular}{|c|c|c|c|c|c|c|c|c|c|}
\hline & & \multicolumn{6}{|c|}{2014} & \multirow[t]{2}{*}{ Total $(\%)$} & \multirow[t]{2}{*}{ Decrement $(\%)$} \\
\hline & & $\begin{array}{r}\text { Arable } \\
\text { land }\end{array}$ & $\begin{array}{r}\text { forest } \\
\text { land }\end{array}$ & $\begin{array}{r}\text { Grass } \\
\text { land }\end{array}$ & $\begin{array}{r}\text { Water } \\
\text { area }\end{array}$ & $\begin{array}{l}\text { Land for urban \& } \\
\text { rural residents }\end{array}$ & $\begin{array}{r}\text { Used } \\
\text { land }\end{array}$ & & \\
\hline \multirow[t]{6}{*}{1985} & Arable land & 56.80 & 20.83 & 18.08 & 2.79 & 1.41 & 0.08 & 2.39 & 1.03 \\
\hline & Forest land & 1.50 & 82.48 & 15.23 & 0.49 & 0.15 & 0.15 & 46.88 & 8.21 \\
\hline & Grass land & 1.45 & 16.34 & 81.74 & 0.29 & 0.11 & 0.07 & 50.47 & 9.21 \\
\hline & Water area & 0.45 & 3.57 & 15.07 & 80.82 & 0.01 & 0.08 & 0.17 & 0.03 \\
\hline & Land for urban \& rural residents & 16.82 & 13.43 & 10.00 & 16.22 & 43.53 & 0.00 & 0.04 & 0.02 \\
\hline & Used land & 0.00 & 22.34 & 31.50 & 0.84 & 0.00 & 45.32 & 0.04 & 0.02 \\
\hline \multicolumn{2}{|c|}{ Total (\%) } & 2.80 & 47.43 & 48.87 & 0.58 & 0.18 & 0.13 & 100 & \\
\hline \multicolumn{2}{|c|}{ Decrement $(\%)$} & 1.44 & 8.77 & 7.62 & 0.45 & 0.16 & 0.11 & 1.44 & \\
\hline \multicolumn{2}{|c|}{ Added area $\left(\mathrm{km}^{2}\right)$} & 89.92 & 121.21 & -351.29 & 91.17 & 30.21 & 18.79 & 89.92 & \\
\hline
\end{tabular}

and water area were increased by 89.91 and $91.16 \mathrm{~km}^{2}$, respectively, and their total increment exceeded the increment of forest land in this period. The increased arable land was mainly forest land and grass land, with large ratio for conversion between forest land and grass land. With social development of society, land for urban and rural residents was increased gradually.

The Table 2 showed the conversion matrixes for typical land use types at upper reaches of Minjiang River at different time periods. During the period of 1985-1995, the converted land area accounted for $19.04 \%$ of the total land use area, mainly involving conversion between high and moderate coverage grass land. Some shrub areas were converted to moderate coverage grass land, and the moderate coverage grass land was mainly converted to high coverage grass land, which accounted for $5.46 \%$ of the total area. During the period of 1995-2005, the land use conversion area was $35.5 \%$, still dominated by the conversion between high and moderate coverage grass land. The high coverage grass land was converted to low coverage grass land, with a ratio of $5.09 \%$ and the shrub area was converted to moderate coverage grass land at the same time. However, the land use conversion area was only $1.16 \%$ during the period of 2005-2014, mainly involving conversion from shrub to other land use types, i.e. forest land $(0.31 \%)$, low coverage grass land $(0.04 \%)$ and dry land $(0.04 \%)$.

\subsection{Changes in land use pattern at landscape level}

The land use pattern at landscape level in the upper reaches of Minjiang River was shown in Table 3. The landscape density (PD, ED) at the whole basin was characterized by decreasing at first and then increasing. The landscape density and the number of patches reached the maximum in 2014. The landscape shape index (LSI) and mean fractal dimension (FRAC_MN) could reflect the type and shape of landscape and the complexity of boundary. The increasing LSI and FRAC_MN during 1985-1995 indicated that during the land development period, there was a lack of effective plan- ning, and the large-scale tree cutting and grazing would induce continuous deterioration of natural vegetation and fragmentation of land type. However, the increasing trends of LSI and FRAC_MN during 1995-2014 might be highly related to local grain for green policy implemented in later 1990s. The CONTAG reflects the cluster degree of different patch type in landscape. A higher value indicates better connectivity of patches dominated by few large patches or of same type in the landscape. With space information included, the CONTAG is the most important index to describe landscape pattern. The high CONTAG in the study indicated the good connection the dominant patch types of forest land and grass land, while the gradually decreasing trend implied the growing interference effect of human activities, and large patches dominated by forest land and grass land were disturbed in social development, causing the connectivity decreased. The DIVISION refers to separation degree of different patch individuals distributed in some landscape. The entire study area had a distinct nature gradient and limited changes in DIVISION. The SHDI can reflect the landscape heterogeneity, and was especially sensitive to unbalanced distribution of various patches types in the landscape, which emphasized the contribution of rare patch types. The SHDI in the study area was relatively large and showed land-use types are increasingly enriched during 1985-1995, but it was followed closely by decreasing.

In conclusion, changes in land use of upper reaches of Minjiang River were mainly characterized by the exchange of land use types between natural forest land and grass land since 1985. The policy of grain for green promoted the increase in arable land area, but these change in arable land were less obvious compared to the changes in forest and grass land. The social development in the early 20th century protected the ecological environment, but also expanded the influence of human activities. 
Table 2. Conversion matrixes for typical land use types from 1985 to 2014 (\%).

\begin{tabular}{|c|c|c|c|c|c|c|c|c|c|c|}
\hline & & $\begin{array}{l}\text { Dry } \\
\text { land }\end{array}$ & $\begin{array}{r}\text { Forest } \\
\text { land }\end{array}$ & Shrub & $\begin{array}{r}\text { Open forest } \\
\text { land }\end{array}$ & $\begin{array}{r}\text { High coverage } \\
\text { grass land }\end{array}$ & $\begin{array}{r}\text { Moderate coverage } \\
\text { grass land }\end{array}$ & $\begin{array}{r}\text { Low coverage } \\
\text { grass land }\end{array}$ & $\begin{array}{r}\text { Urban } \\
\text { land }\end{array}$ & $\begin{array}{r}\text { Rural residential } \\
\text { land }\end{array}$ \\
\hline \multirow[t]{9}{*}{ 1985-1995 } & Dry land & 71.37 & 3.11 & 12.34 & 1.53 & 2.09 & 8.56 & 0.59 & 0.03 & 0.14 \\
\hline & Forest land & 0.25 & 88.25 & 5.24 & 0.28 & 1.23 & 4.58 & 0.17 & 0.00 & 0.00 \\
\hline & Shrub & 1.01 & 3.10 & 85.93 & 0.25 & 1.29 & 7.98 & 0.41 & 0.00 & 0.01 \\
\hline & Open forest land & 1.46 & 1.75 & 3.10 & 85.27 & 1.88 & 5.89 & 0.57 & 0.00 & 0.01 \\
\hline & High coverage grass land & 1.52 & 3.41 & 5.60 & 0.33 & 51.09 & 37.96 & 0.08 & 0.00 & 0.01 \\
\hline & Moderate coverage grass land & 0.34 & 2.23 & 3.88 & 0.35 & 13.10 & 79.58 & 0.42 & 0.00 & 0.01 \\
\hline & Low coverage grass land & 0.71 & 1.83 & 4.22 & 0.41 & 6.12 & 0.63 & 86.05 & 0.00 & 0.03 \\
\hline & Urban land & 7.57 & 0.72 & 6.25 & 1.49 & 3.47 & 0.00 & 3.87 & 0.00 & 0.00 \\
\hline & Rural residential land & 11.93 & 2.50 & 9.05 & 0.79 & 3.24 & 1.35 & 8.53 & 0.98 & 0.13 \\
\hline \multirow[t]{9}{*}{ 1995-2005 } & Dry land & 58.65 & 4.45 & 10.76 & 3.15 & 7.34 & 9.65 & 1.57 & 0.11 & 0.70 \\
\hline & Forest land & 0.59 & 74.27 & 9.94 & 2.51 & 5.34 & 6.34 & 0.47 & 0.00 & 0.01 \\
\hline & Shrub & 2.23 & 10.86 & 64.29 & 4.32 & 8.09 & 8.09 & 1.19 & 0.01 & 0.04 \\
\hline & Open forest land & 2.53 & 9.89 & 9.22 & 61.93 & 7.96 & 7.05 & 0.30 & 0.03 & 0.19 \\
\hline & High coverage grass land & 1.69 & 7.32 & 9.14 & 3.36 & 23.64 & 52.22 & 1.79 & 0.00 & 0.05 \\
\hline & Moderate coverage grass land & 1.42 & 4.81 & 7.97 & 2.19 & 11.40 & 70.84 & 0.89 & 0.01 & 0.02 \\
\hline & Low coverage grass land & 1.10 & 3.86 & 14.23 & 4.54 & 4.25 & 19.92 & 50.11 & 0.14 & 1.19 \\
\hline & Urban land & 25.55 & 0.01 & 2.20 & 2.11 & 0.60 & 4.36 & 0.00 & 52.07 & 0.00 \\
\hline & Rural residential land & 22.12 & 3.66 & 9.25 & 0.67 & 4.03 & 13.00 & 3.29 & 2.18 & 23.79 \\
\hline \multirow[t]{9}{*}{ 2005-2014 } & Dry land & 95.48 & 0.09 & 1.06 & 0.32 & 1.09 & 0.19 & 0.02 & 0.03 & 0.44 \\
\hline & Forest land & 0.03 & 99.45 & 0.08 & 0.12 & 0.06 & 0.05 & 0.06 & 0.00 & 0.01 \\
\hline & Shrub & 0.16 & 1.39 & 97.83 & 0.07 & 0.06 & 0.15 & 0.17 & 0.00 & 0.03 \\
\hline & Open forest land & 0.07 & 0.15 & 0.09 & 98.89 & 0.03 & 0.03 & 0.54 & 0.00 & 0.01 \\
\hline & High coverage grass land & 0.16 & 0.15 & 0.23 & 0.21 & 99.07 & 0.09 & 0.03 & 0.00 & 0.01 \\
\hline & Moderate coverage grass land & 0.05 & 0.06 & 0.07 & 0.07 & 0.07 & 99.56 & 0.01 & 0.00 & 0.01 \\
\hline & Low coverage grass land & 0.49 & 0.06 & 0.37 & 0.54 & 0.79 & 0.17 & 97.49 & 0.00 & 0.02 \\
\hline & Urban land & 1.98 & 0.00 & 0.00 & 0.00 & 0.00 & 0.00 & 0.00 & 97.10 & 0.92 \\
\hline & Rural residential land & 10.44 & 0.25 & 1.99 & 0.00 & 0.00 & 0.04 & 0.09 & 0.00 & 80.50 \\
\hline
\end{tabular}

Table 3. Landscape indexes of land use from 1985 to 2014.

\begin{tabular}{rrrrrrrr}
\hline Year & PD & ED & LSI & FRAC_MN & CONTAG & DIVISION & SHDI \\
\hline 1985 & 0.1474 & 14.6405 & 68.2270 & 1.0941 & 68.6634 & 0.9496 & 1.6549 \\
1995 & 0.1432 & 14.6823 & 68.4190 & 1.0948 & 67.3052 & 0.9465 & 1.6821 \\
2005 & 0.4018 & 24.5776 & 93.2695 & 1.0898 & 63.2793 & 0.9470 & 1.6380 \\
2014 & 0.4749 & 25.3151 & 96.0111 & 1.0838 & 62.8380 & 0.9487 & 1.6491 \\
\hline
\end{tabular}

\subsection{Hydrological response to land use changes}

The hydrological and meteorological data in Dujiangyan Station were used in this study to analyze annual trend of precipitation and runoff during 1959-2008. The results were shown in Fig. 2. The precipitation was overall decreased by $1.9 \mathrm{~mm}$ per year; meanwhile, the annual mean flow was also showed a decreasing trend, with average decreasing speed of $1.5 \mathrm{~m}^{3} \mathrm{~s}^{-1}$ per year, and the annual runoff volume decreased at a rate of $47.5 \times 10^{6} \mathrm{~m}^{3}$ per year. The changes in precipitation and runoff were nearly synchronous, because precipitation is the main factor to constitute runoff. Therefore, based on the precipitation and runoff data from 1959 to 2008, we established statistical equations (Table 4) for precipitation and runoff during the period 1959-2008, 19851995 and 1996-2008 through regression analysis, respectively. These equations represent the relationship between rainfall and runoff under different land use impacts.

The $R^{2}$ of regression equation at each period were larger than 0.6 , indicating the close relationship between runoff and
Table 4. Statistical regression analysis and statistical models for runoff and precipitation in different periods.

\begin{tabular}{llr}
\hline Period & Correlation regression equation* & $R^{2}$ \\
\hline $1959-2008$ & (1) $Q=-1.329 E-05 P^{2}+0.588 P+12.673$ & 0.747 \\
$1985-1995$ & (2) $Q=0.623 P-24.545$ & 0.798 \\
$1996-2008$ & (3) $Q=0.537 P+34.646$ & 0.670 \\
\hline
\end{tabular}

* $Q$ and $P$ in the equations are annual mean flow and precipitation.

precipitation. Therefore, the statistical model could relatively accurately describe this relation. The monomial coefficient in Eq. (3) is 0.537 , smaller than 0.623 in Eq. (2), indicating the runoff generation capacity in the 1996-2008 was decreased compared with that in the previous 10 years.

Since 1970s, the precipitation and runoff process in the basin were gradually weakened, and these may partially due to the land use changes. The predicted runoff from 19851995 was calculated with the statistical model in Eq. (3) to obtain the comparative predicted values under the same pre- 


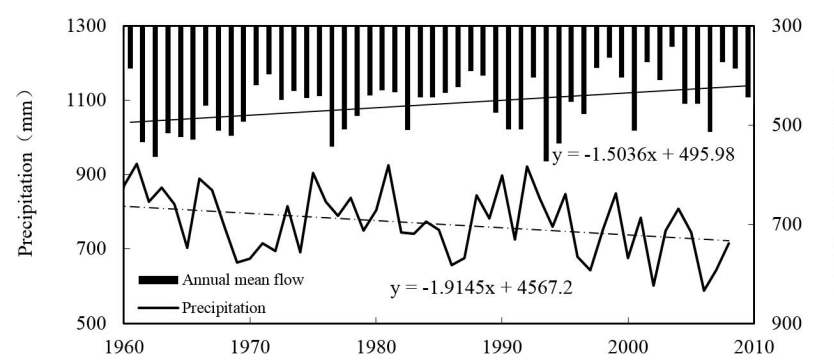

Figure 2. Precipitation and annual mean flow in Dujiangyan from 1959 to 2008.

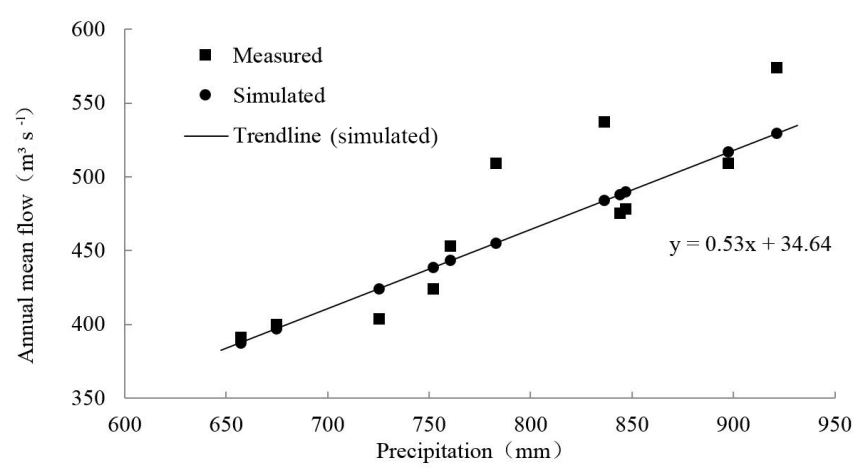

Figure 3. Comparison of simulated and measured annual mean flow from 1985 to 1995 .

cipitation and different land use conditions. The comparison of simulated and measured flow during 1985-1995 was shown in Fig. 3. The simulated annual mean flow was highly consisted with the measured flow, but there were still some differences. The runoff generation capacity was relatively low under the same land use conditions, and the simulation decreased by $9.19 \mathrm{~m}^{3} \mathrm{~s}^{-1}$ compared with observation. The land use pattern in the study area was dominated by grass land and forest land. Since the boom of forest resource exploitation appeared in the upper reaches of Minjiang River in 1980s and the "wood finance" appeared in the counties and districts, the forest land types were damaged. Previous research showed that vegetation condition influenced the surface runoff, which is an important part (Xiao et al., 2006) of the eco-hydrological functions, such as water conservation, preserving water and soil, reducing peak-flow and flood, and reducing sediment yield. Forest land has flood intercepting, low water supply, water purifying and other functions (Abari et al., 2017). The destruction of forest land reduced the water and soil reservation capacity, which was the main reason of the higher measured flow.

The comparison between simulated and measured annual mean flow from 1996-2008 was shown in Fig. 4. Similar with the comparison trend in the period of 1985-1995, the simulated flow from statistical model was still lower than the measured value under the same land use conditions of forest land destroyed. The simulated flow was $1.04 \mathrm{~m}^{3} \mathrm{~s}^{-1}$

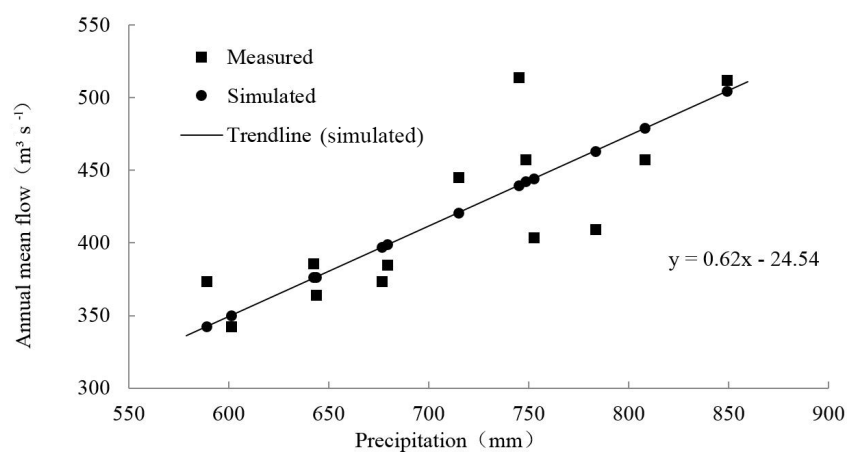

Figure 4. Comparison of simulated $r$ and measured annual mean flow from 1996 to 2008.

decreased than the measured value on average. This result was related to the increase in arable area and decrease in grass land area in the study area. The growth rate of population in the upper reaches of Minjiang River kept at about $10 \%$ since 1995 , while the agriculture population was only increased by 5000 during 1995-2000. Special geomorphic features, less cultivable land area and unchanged traditional cultivation method in the study area compelled the people to reclaim the hillside land (Zhao et al., 2006; Sichuan Census Office and Sichuan Provisional Bureau of Statistics, 2012), expand animal husbandry and turn forest land into grass land. In such cases, grass land was severely degraded due to influence from animal husbandry. Baneful influence was brought to ecological environment, water and soil loss was intensified, and measured annual mean flow was increased. The restoration of ecological environment needed to be further reinforced.

\section{Conclusions}

The development in economy and society changed people's way of life and land use, which affected the water cycle process between rainfall and surface runoff in the basin. According to the analysis of land use pattern in last 30 years through hydrological and precipitation data and establishing of statistical regression model, the conclusion is as follows:

1. During the period of 1985-2014, dynamic changes in land use were mainly dominated by the change of forest and grass land and characterized by the exchanges of various types between natural forest and grass land. Arable land was changed remarkably due to corresponding policies. During the period of 1985-1995, the land use pattern and the types of forest and grass land were fragmented. The ecological environment was degraded and arable land area was decreased. During the period of 1995-2014, a large number of shrub wood was changed into grass land and the arable area was increased due to the impact of human activities, resulting in higher heterogeneity of land use pattern. 
2. The decrease in runoff at the whole basin was attributed to the decrease in rainfall, which was closely related to forest and grass land patterns, while the complex physical mechanism should be further studied. Statistic models at different times in this study show that: from 19851995, simulated flow was $9.19 \mathrm{~m}^{3} \mathrm{~s}^{-1}$ lower than the measured value. As for the land use, the forest and grass land were mainly disturbed and the ecosystem maintenance as well as the water supply function for the forest were seriously damaged. From 1995-2008, the simulated value was $1.04 \mathrm{~m}^{3} \mathrm{~s}^{-1}$ lower than the measured value. Due to the contradiction between the development in human society and the limited resources in agriculture was gradually intensified, the arable land area was increased and the shrub wood as well as grass land were degraded. It is still necessary to increase efforts on protecting the ecological environment and maintaining the sustainable development of ecological functions.

Data availability. Precipitation data is provided by the China Meteorological Administration and can be downloaded from its official website. Hydrological data and land use data are not publicly accessible. Runoff data are provided by the Survey Bureau of The Hydrology and Water Resources, and land use data are provided by China Institute of Water Resources and Hydropower Research.

Competing interests. The authors declare that they have no conflict of interest.

Special issue statement. This article is part of the special issue "Innovative water resources management - understanding and balancing interactions between humankind and nature". It is a result of the 8th International Water Resources Management Conference of ICWRS, Beijing, China, 13-15 June 2018.

Acknowledgements. This work is supported by the National Science Foundation of China (No. 51579161, 51779160) and National Program on Key Basic Research Project (2015CB452701).

Edited by: Zongxue Xu

Reviewed by: two anonymous referees

\section{References}

Abari, M. E., Majnounian, B., Malekian, A., and Jourgholami, M.: Effects of forest harvesting on runoff and sediment characteristics in the Hyrcanian forests, northern Iran, Eur. J. Forest Res., 136, 375-386, 2017.

Bewket, W. and Sterk, G.: Dynamics in land cover and its effect on stream flow in the Chemoga watershed, Blue Nile basin, Ethiopia, Hydrol. Process., 19, 445-458, 2005.
Bu, R., Hu, M., Chang, Y., Li, X., and He, H.: Correlation Analysis between Landscape Indexes, Acta Ecologica Sinica, 25, 27642775, 2005.

Bütof, A., Von Riedmatten, L. R., Dormann, C. F., SchererLorenzen, M., Welk, E., and Bruelheide, H.: The responses of grassland plants to experimentally simulated climate change depend on land use and region, Glob. Change Biol., 18, 127-137, 2015.

Hao, Z. and $\mathrm{Su}, \mathrm{Z}$.: Effects of land use change on runoff in the typical areas in Haihe River basin, Advances in Water Science, 26, 491-499, 2015.

Huang, M. and Zhang, L.: Hydrological responses to conservation practices in a catchment of the Loess Plateau, China, Hydrol. Process., 18, 1885-1898, 2004.

Kalnay, E. and Cai, M.: Impact of urbanization and land use change on climate, Nature, 423, 528-531, 2003.

Lambin, E. F., Baulies, X., Bockstael, N. E., Fischer, G., Krug, T., Leemans, R., Moran, E. F., Rindfuss, R. R., Skole, D. L., and Turner, I. I.: Land use and Land-Cover Change: Implementation Strategy, Shock, 30, 10-29, 2002.

Liu, J., Liu, M., Tian, H., Zhuang, D., Zhang, Z., Zhang, W., Tang, X., and Deng, X.: Spatial and temporal patterns of China's cropland during 1990-2000: An analysis based on Landsat TM data, Remote Sens. Environ., 98, 442-456, 2005.

Liu, R. and Zhu, D.: Methods for Detecting Land Use Changes Based on the Land Use Transition Matrix, Resources Science, 32, 1544-1550, 2010.

Napoli, M., Massetti, L., and Orlandini, S.: Hydrological response to land use and climate changes in a rural hilly basin in Italy, Catena, 157, 1-11, 2017.

Potter, K. W.: Hydrological impacts of changing land management practices in a moderate-sized agricultural catchment, Water Resour. Res., 27, 845-855, 1991.

Ravan, S. A. and Roy, P. S.: Satellite Remote Sensing for Ecological Analysis of Forested Landscape, Plant Ecol., 131, 129-141, 1997.

Sichuan Census Office, and Sichuan Provisional Bureau of Statistics: Tabulation on the 2010 Population census of sichuan province, China Statistics Press, Sichuan, 2012.

Wang, G., Zhang, Y., Liu, G., and Chen, L.: Impact of Land Use Change During 1967-2000 in Ma Ying River Basin on River Runoff, Science China, 35, 671-681, 2005.

Xiao, D. and Bu, C.: Spatial Ecology and Landscape Heterogeneity, Acta Ecologica Sinica, 17, 453-461, 1997.

Xiao, J., Zhang, Z., and Wu, J.: Preliminary Study about Impact of Slope Scale and Forested Land Vegetation on Surface Runoff and Soil Moisture, Research of soil and Water Conservation, 13, 227-231, 2006.

Zhao, Y., He, X., Hu, Y., and Chang, Y.: Land Use/Land Cover Changes and driving forces in the upper reaches of Minjiang River, Chinese Journal of Applied Ecology, 17, 862-866, 2006.

Zhou, J., Lei, L., Shi, P., Wang, L., Wei, W., Liu, H., Amp, G., and University, N. N.: Response of runoff to the climate and land use pattern changes in Shiyang River Basin, Acta Ecologica Sinica, 35, 3788-3796, 2015. 